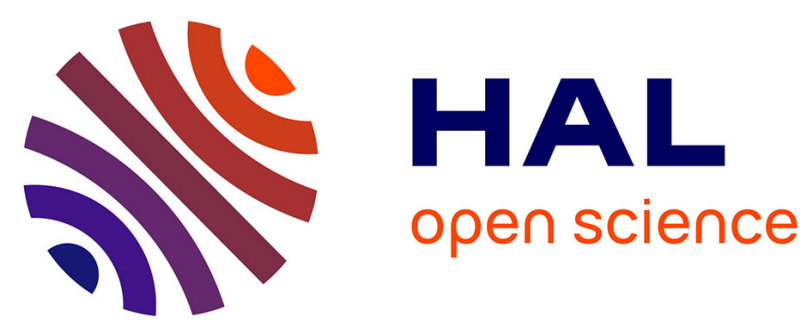

\title{
Impact speed dependency of the ductile failure threshold temperature for a plasticized polyvinylchloride
}

Clément Bertaux, Nicolas Amouroux, C. Ovalle Ovalle Rodas, Lucien

Laiarinandrasana

\section{- To cite this version:}

Clément Bertaux, Nicolas Amouroux, C. Ovalle Ovalle Rodas, Lucien Laiarinandrasana. Impact speed dependency of the ductile failure threshold temperature for a plasticized polyvinylchloride. Continuum Mechanics and Thermodynamics, 2021, 33 (6), pp.2375-2390. 10.1007/s00161-021-01026y . hal-03359093

\section{HAL Id: hal-03359093 https://hal.science/hal-03359093}

Submitted on 30 Sep 2021

HAL is a multi-disciplinary open access archive for the deposit and dissemination of scientific research documents, whether they are published or not. The documents may come from teaching and research institutions in France or abroad, or from public or private research centers.
L'archive ouverte pluridisciplinaire HAL, est destinée au dépôt et à la diffusion de documents scientifiques de niveau recherche, publiés ou non, émanant des établissements d'enseignement et de recherche français ou étrangers, des laboratoires publics ou privés.

\section{(c)(1)}

Distributed under a Creative Commons Attribution| 4.0 International License 


\title{
Impact speed dependency of the ductile failure threshold temperature for a plasticized polyvinylchloride
}

\author{
C. Bertaux $\cdot$ N. Amouroux $\cdot$ C. Ovalle $\cdot$ L. Laiarinandrasana
}

\begin{abstract}
With the goal of ensuring the security of passengers for automotive industry, the present work addresses the temperature and impact speed envelope allowing ductile failure of plasticized PVC to be obtained. A database of about 250 test results has been constructed for various conditions at ten test temperatures, four impact speeds and two specimen geometries (with or without scoring). The desired ductile failure was characterized by the shape of the load versus deflection curve together with the fracture surface morphology obtained. The temperatures for obtaining ductile failure threshold $\left(T_{\mathrm{dth}}\right)$ have been plotted as a function of the impact speeds for the two geometries. A gap of $20^{\circ} \mathrm{C}$ on the $T_{\mathrm{dth}}$ was highlighted between the two geometries. Additionally, the impact strength of the plasticized PVC under study was estimated to be $0.25 \mathrm{~kJ} / \mathrm{m}^{2}$.
\end{abstract}

Keywords Impact test · Polymers · Ductile/Brittle transition temperature

\section{Introduction}

Airbag spreading is a major concern for the security of the passengers by the automotive industry. The design and elaboration of the dashboard is one of the key features to obtain the required specifications. Plasticized PVC skins are commonly used for the top surface of the three layers of the dashboard.

In Fig. 1, full scale tests consisting of airbag deployment were performed at three characteristic temperatures: $-35^{\circ} \mathrm{C} ; 23^{\circ} \mathrm{C}$ and $85^{\circ} \mathrm{C}$. The impact speed was estimated to be $25 \mathrm{~m} / \mathrm{s}$. Figure 1 a shows the location of the passenger's airbag subjected to the test. The three pictures on the right hand side corresponded to the deformed skin at the onset of the expansion of the bag (in white).

C. Bertaux · C. O. Rodas $\cdot$ L. Laiarinandrasana $(\bowtie)$

MINES ParisTech, MAT - Centre des matériaux, CNRS UMR 7633, PSL University, BP 87, 91003 Evry, France

E-mail: lucien.laiarinandrasana@mines-paristech.fr

C. Bertaux

E-mail: clement.bertaux@mines-paristech.fr

C. O. Rodas

E-mail: cristian.ovalle_rodas@mines-paristech.fr

N. Amouroux

Westlake Couponds Holding 1bis rue Maurice Hollande, 51100 Reims, France

E-mail: nicolas.amouroux@westlake.com 


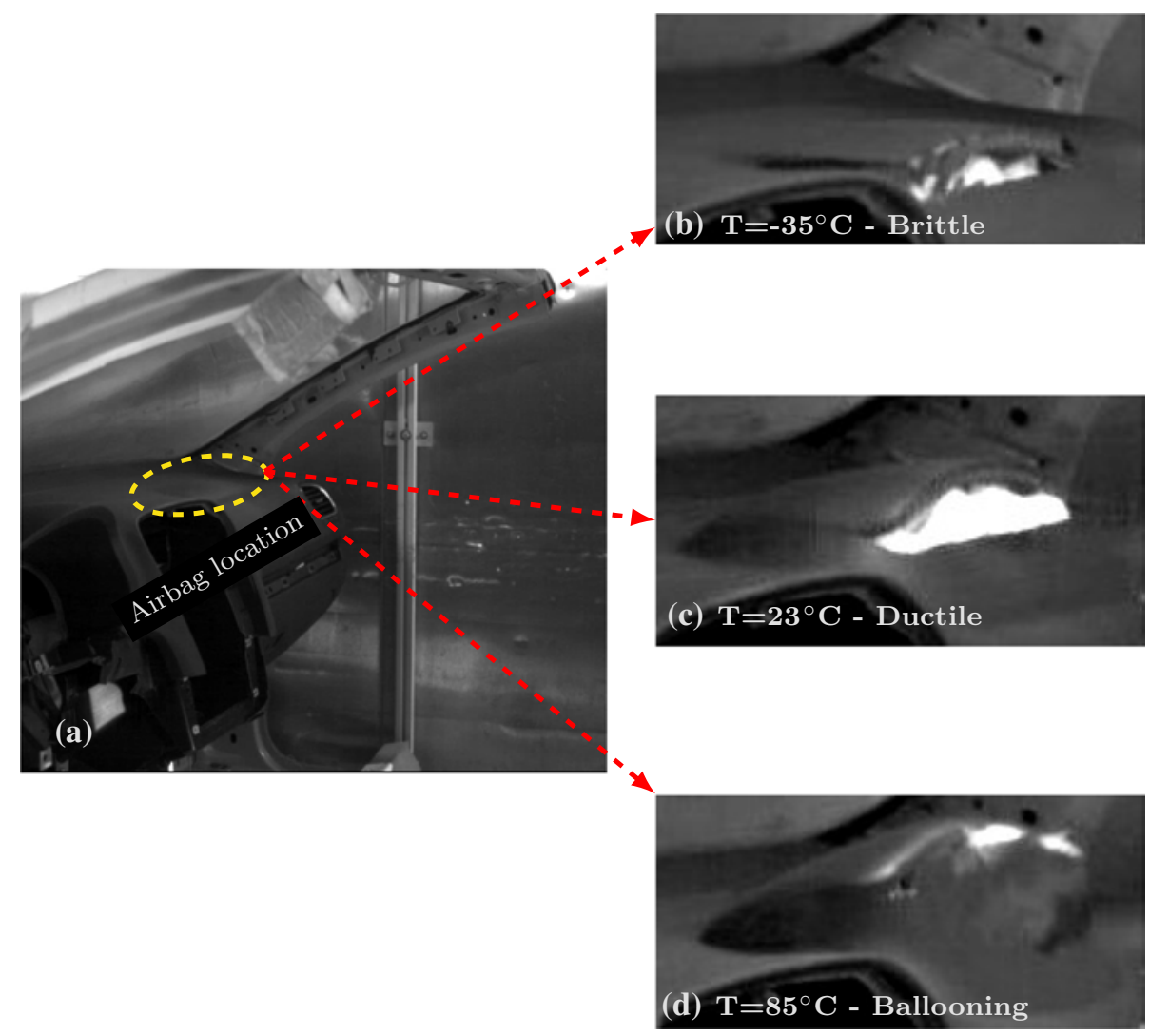

Fig. 1 Test at full scale of an airbag deployment: a Dashboard at the passenger's side indicating the airbag location; $\mathbf{b}$ brittle failure at $-35^{\circ} \mathrm{C}$, fragments of material can be observed; $\mathbf{b}$ correct ductile tearing at $23^{\circ} \mathrm{C}$; $\mathbf{c}$ ballooning effect at $85^{\circ} \mathrm{C}$ inducing delay or nonopening

- At $-35^{\circ} \mathrm{C}$ (Fig. 1b), a brittle failure of the skin occurred with almost no deformation. The presence of black remaining macrofibrils can be noticed; that transformed into pieces of material. This risk of fragmentation [1] and projection of the pieces of the material, should be suppressed;

- At $23^{\circ} \mathrm{C}$ (Fig. 1c), a net ductile tearing of the skin was observed following the scoring direction and accompanied by the deformation of top surface of the airbag box. This is the ideal case;

- At $85^{\circ} \mathrm{C}$ (Fig. 1d), a significant deformation of the box together with an extreme extension of the skin delayed the opening time, if it occurred as ballooning could prevent the opening of the box. This situation is the most dangerous even though the ultimate failure could also be qualified as ductile.

The objective of the present work has been to determine the range of test temperatures and impact speeds which allowed an ideal ductile failure of the skin as in Fig. 1c to be obtained. Furthermore, the effects of a crack like defect on the material properties have been investigated.

The concept of Ductile to Brittle Transition Temperature (DBTT) has been commonly used to characterize materials for such applications. In the literature, the DBTT has been used to characterize various industrial structures composed of metals as well as polymers. Three kinds of experiments have been used to define the DBTT:

- Tensile stress-strain curves at various temperatures, strain rates and rubber particles volume fractions of rubber particles [2-7];

- Charpy or Izod impact tests at various temperatures and rubber particles volume fractions $[3,8]$;

- Fracture mechanics tests for a given specimen geometry (Compact tension or Single Edge Notch Bending) to plot the fracture toughness at various temperatures $[9,10]$.

The method used to determine the DBTT depends on the above-mentioned experimental results. For the stress-strain curves, the strain at break or the yield stress are plotted with respect to the temperature or the strain rate. The change of the slope of this diagram allows the determination of the DBTT [2,4-7]. For the Charpy 

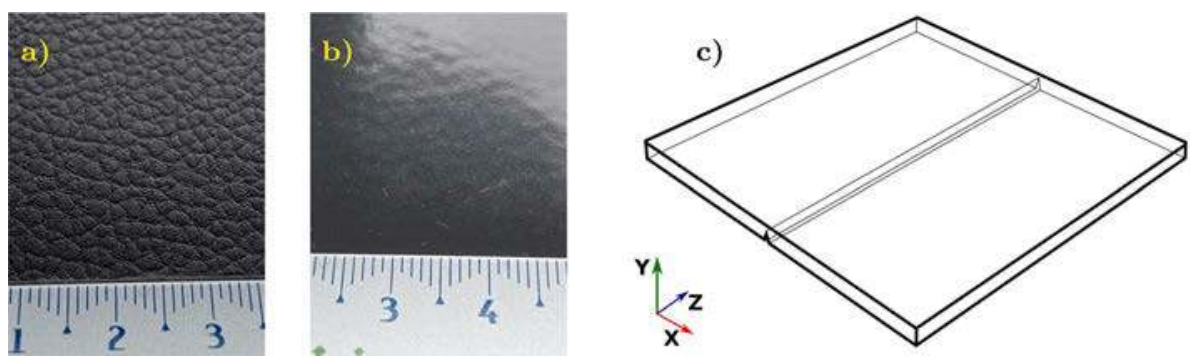

Fig. 2 The plasticized PVC thin plate: a top surface of the skin where patterns can be observed; $\mathbf{b}$ smooth and shiny inner surface of the skin (no pattern); $\mathbf{c}$ sketch of inner scoring of the thin plate

or Izod tests, the impact strength is plotted with respect to the temperature (the impact speed being fixed). This impact strength generally exhibits upper and lower plateaux called "shelves". The DBTT is defined as representative of the transition between the upper and lower shelves [3,8]. The same concept as that used for impact strength can be extended to fracture mechanics tests, which are carried out under quasi-static loading $[9,10]$. Instead of using the impact strength of the material, the fracture toughness is plotted with respect to test temperature. This plot can also be parametrized by the cross-head speed.

The present study introduces the new concept of Ductile Failure Threshold Temperature $\left(T_{\mathrm{dth}}\right)$, which is a temperature higher than the DBTT, and located at the intersection between the transition zone and the beginning of the upper shelf energy. Indeed, the objective here is to define the temperature/speed where the failure is "just ductile" for the material of the study. The evolution of the $T_{\mathrm{dth}}$ has been investigated with respect to the impact speed for a rather soft material: the plasticized PVC. The relevant parameters defining the $T_{\mathrm{dth}}$, such as the stiffness, the deflection/load at break and the fracture energy were then analysed.

The paper is divided into 4 sections. The first one describes the material and the methods utilized throughout the work. The second section details the experimental results. This is followed by a section dealing with the discussion. The section corresponding to the conclusion and future work ends then the manuscript.

\section{Material and methods}

\subsection{Materials and specimens}

Four various polyvinylchloride (PVC) powder compositions, marketed under the trademark NAKAN, were provided by the Westlake Global Compound, the industrial partner for the study. They were transformed into skins: the top element of the three layers composing the dashboard in the automotive industry. The powders were composed of the same elements, such as PVC resins, plasticizers, pigments and stabilizers [11-14]. But the four skins differed in the resin grades and the plasticizers/stabilizers ratios. The present work focuses on one grade: the most marketed by the company.

The skins with thicknesses of $1.2 \mathrm{~mm} \pm 0.1 \mathrm{~mm}$ were obtained by transformation of the powders using the slush moulding method $[15,16]$. It allowed the creation of shapes and patterned surfaces which would have been difficult to produce with other methods. It should be noted that the external wall (apparent surface on the dashboard) was patterned for softness in touch and aesthetic purposes (Fig. 2a), whereas the internal wall exhibited a smooth and shiny surface (Fig. 2b). From the obtained skins, $90 \mathrm{~mm} \times 90 \mathrm{~mm}$ square samples were machined using a robotic cutting machine. In the following, these samples will be noted as plates without scoring or unscored samples.

In order for the sample to be more representative of the dashboard skin, a scoring was added on the bottom (smooth) surface of the skins with the same robotic machine for better reproducibility (Fig. 2c). Half of the samples showed this scoring which is considered here as a crack like defect. Actually, the robot cuts the material to retain a ligament thickness of $0.6 \mathrm{~mm}$. Thus, the desired ratio between the score depth and the total thickness was about 0.5. This implied an uncertainty for the score depth ratio due to the real thickness of the skin and the roughness of the top surface pattern. These samples will be referred to as plates with scoring or scored samples. 


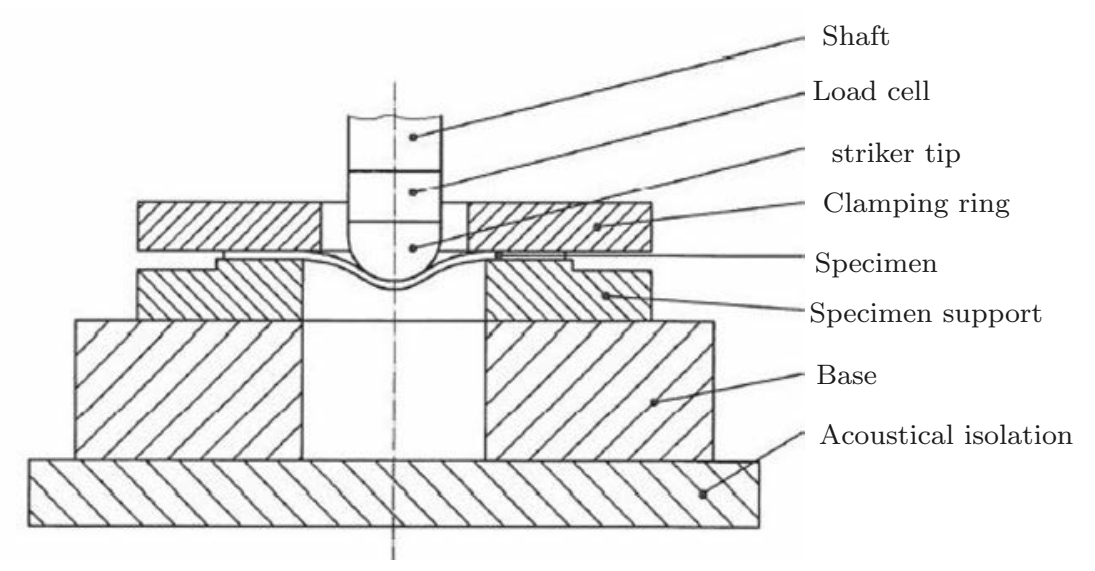

Fig. 3 Experimental setup to fix the plate specimen. Note the circular clamping around the hemispherical impactor tip [17]

\subsection{Experimental procedures}

\subsubsection{Impact tests}

All the impact tests were carried out using an Instron CEAST9350 drop tower impact system [17]. The samples, consisting of a thin and soft plates, had to be gripped along a circular section. The CEAST 9350 machine consisted of four different parts, each with distinct functions.

Figure 3 details the clamping system, used to fix the edges with circular jaws with a prescribed diameter of $40 \mathrm{~mm}$. The clamping device was calibrated for the striker (see below) to impact the centre of the plate. For scored plates, a tracking system was developed to position the sample so that the scoring went through the centre of the impact zone. This scoring also implied a non-coaxiality: the deformed plate could no longer be considered as axisymmetric.

The specimen together with its clamping device was placed in a thermostatic chamber, with a temperature range from $-70^{\circ} \mathrm{C}$ to $+150{ }^{\circ} \mathrm{C}$. The temperature gradient guaranteed by the constructor was about $\pm 2{ }^{\circ} \mathrm{C}$. When the temperature was stabilized in the chamber, an additional delay of thirty minutes was imposed before the test began to ensure that the material was at the prescribed test temperature. However, it should be noted that there was a small hatch on the chamber, which opened just before the impact. This may have induced temperature uncertainties.

In this work, the test temperatures explored were $(-24,-21,-18,-15,-12,-9,-6,-3,0,5,10$, $\left.15,20,25^{\circ} \mathrm{C}\right)$. The temperature range was adapted to the prescribed impact speeds. For test temperatures lower than room temperature, liquid nitrogen was used as a coolant. A resistance heating system was utilized for higher temperatures.

The striker consisted of a cylindrical metal stem with a semi-spherical end and a curvature radius of $2 \mathrm{~cm}$. The drop system was provided with a given mass (here $5.3 \mathrm{~kg}$ ). For rigid plastics, the standard recommendations consist of an impact speed of $4.4 \mathrm{~m} / \mathrm{s}$. For the present work, the selected impact speeds were: $(2 ; 4.4 ; 6 ; 10$ $\mathrm{m} / \mathrm{s})$.

The same experimental programme was performed on thin plates with and without scoring. Each testing condition (test temperature - impact speed) was repeated three times for reproducibility purposes.

The rough data obtained after the tests were composed of the running time, the load and the initial velocity of the impactor. The software of the testing machine calculates then the velocity at any time, as follows:

$$
v(t)=v_{0}-\frac{1}{m} \int_{0}^{t} F(t) \mathrm{d} t
$$

where:

$-v_{0}(\mathrm{~m} / \mathrm{s})$ is the initial speed of the impactor before hitting the sample ;

$-m$ is the mass of the striker, here $m=5.3 \mathrm{~kg}$;

- $F(t) \mathrm{d} t$ (N.s) is the impulse given by the striker to the specimen. 
The velocity as calculated by Eq. (1) tends to decrease during the impact loading.

By means of a second integration, the deflection/displacement ' $d$ ' at any time ' $t$ ' was computed:

$$
d(t)=v_{0} t-\frac{1}{m} \int_{0}^{t^{\prime}}\left[\int_{0}^{t} F(t) \mathrm{d} t\right] \mathrm{d} t^{\prime}
$$

The unit of ' $d$ ' and ' $t$ ' were, respectively, millimetres and seconds.

Knowing the computed displacement ' $d$ ', the CEAST 9350 software delivered the energy absorbed by the sample at any time of the test with the following relation:

$$
E(t)=v_{0} \int_{0}^{t} F(t) \mathrm{d} t-\frac{\left[\int_{0}^{t} F(t) \mathrm{d} t\right]^{2}}{2 m}
$$

allowing to obtain the energy absorbed by the sample until either the maximum load or during the whole test (maximum time).

In the following, the energy computed at the onset of the final failure (drop of the load) named as $E_{\mathrm{F}}$ is of prime interest. The formula in Eq. (3) until the maximum load was systematically checked by directly integrating the area under the load versus deflection curve as follows:

$$
E_{\mathrm{F}}=\int_{0}^{u\left(F_{\max }\right)} F(u) \mathrm{d} u
$$

where:

- ' $u$ ' is the running deflection obtained in Eq. (2);

- $F(u)$ is the load corresponding to the deflection ' $u$ ';

$-u\left(F_{\max }\right)$ is the deflection corresponding to the maximum load ' $F_{\max }$ '.

\subsubsection{Fracture surface patterns}

The fracture surfaces of the broken samples were systematically examined so as to identify the characteristic fracture morphology of a ductile or a brittle surface. To this end, various examination techniques were utilized, starting with the optical camera at the macroscopic scale to the Scanning Electron Microscope (SEM) at the microscopic scale. SEM was thoroughly used for fractography purposes. The surfaces to be observed were systematically coated with $\mathrm{Au} / \mathrm{Pd}(\approx 3$ nm layer thickness).

\subsection{Methods}

As mentioned in Sect. 2.2, the experimental data consisted of the load, the deflection and the energy, synchronized at the same running time. Moreover, the morphology of the fracture surfaces was related to each test.

\subsubsection{Mechanical properties}

For each test, the load versus deflection curve was plotted so as to analyse its specific shape. Then, four main characteristic mechanical parameters were deduced:

- the stiffness of the system that corresponded to the slope of the linear part of the curve;

- the deflection $\left(d_{\mathrm{F}}\right)$ and the load $\left(F_{\mathrm{F}}\right)$ at failure, related to the last point before the abrupt drop of the load i.e. at the onset of the failure;

- the fracture energy $\left(E_{\mathrm{F}}\right)$ determined by integration of the area under the load versus deflection curve, up to $\left(d_{\mathrm{F}}, F_{\mathrm{F}}\right)$ :

$$
E_{\mathrm{F}}=\sum_{i=1}^{F} \frac{\left(F_{i}+F_{i-1}\right)}{2}\left(d_{i}-d_{i-1}\right)
$$

It should be noted that the $E_{\mathrm{F}}$ obtained here was systematically compared with that given by the CEAST using Eq. (4). 
The corresponding fracture surfaces were associated with the test. Then, for each impact speed, the abovementioned mechanical parameters were plotted with respect to the explored test temperatures. The trend of each parameter was determined and analysed.

\subsubsection{Fracture energy versus test temperature}

\section{Reduction in the experimental data}

Each test has been checked using two criteria based on the trend of the load versus deflection curve and the shape of the fractured surfaces. Therefore, the experimental data were classified into three categories, respectively, named as brittle, ductile and transition. All unclassified test results i.e. those which did not match both criteria were rejected for the next steps. Note that this operation was carried out on test results for both scored and unscored samples.

Fracture energy $E_{\mathrm{F}}$

The fracture energy $E_{\mathrm{F}}$ for scored and unscored samples was plotted with respect to the test temperatures for the reduced data.

Typically, for a given impact speed $E_{\mathrm{F}}$ increased continuously with the test temperature giving a "S-shape" curve [18-20]. This S-shaped curve was modelled by using a tan $h$ function [18].

$$
E_{F}(T)=\left(E_{\mathrm{U}}-\frac{\Delta E}{2}\right)+\frac{\Delta E}{2} \tan h\left(\frac{T-T_{\mathrm{dth}}+\frac{\Delta T}{2}}{\frac{\Delta T}{2}}\right)
$$

where:

- $E_{\mathrm{U}}$ is the upper shelf fracture energy value;

- $\Delta E=E_{\mathrm{U}}-E_{\mathrm{L}}$ with $E_{\mathrm{L}}$ the lower shelf fracture energy value;

- $T_{\mathrm{dth}}$ is the Ductile Failure Threshold Temperature;

$-\Delta T$ is the range of the temperature corresponding to the transition domain.

The determination of $T_{\mathrm{dth}}$ was then performed by using an optimization procedure such that the tanh function fitted the reduced experimental data.

\subsubsection{Determination of the temperature/impact speed domain for ductile failure}

The approach proposed in this subsection allowed a determination of $T_{\mathrm{dth}}$ for a given impact speed. By following the same procedure for various impact speeds, two plots could be established between $T_{\mathrm{dth}}$ and the impact speed for the two sample geometries. Therefore, this diagram enabled the domain of test temperature and impact speed to be defined where the net ductile failure was expected.

\subsubsection{Fracture energy per fracture surface}

In the discussion section, an attempt has been made to relate the load to the "working cross section". Indeed, the fracture energy $E_{\mathrm{F}}$ depended on the two specimen geometries (with or without scoring). The fracture surfaces observations allowed an estimation of the area of the fractured surface. Following, a fracture mechanics approach to introduce the energy release rate [9,21-24], it was proposed for the ductile tearing to plot $E_{\mathrm{F}}$ per unit fractured area.

\section{Results}

\subsection{Impact tests}

\subsubsection{Plates without scoring}

Based on the ISO standard [17], the scientific challenge here was similar to that of small punch tests [22] so as to assess the ductile to brittle transition temperature of irradiated metallic materials. The same problematic can be related to that of plug-assisted thermoforming $[25,26]$ where a thin plate is impacted at high temperature 


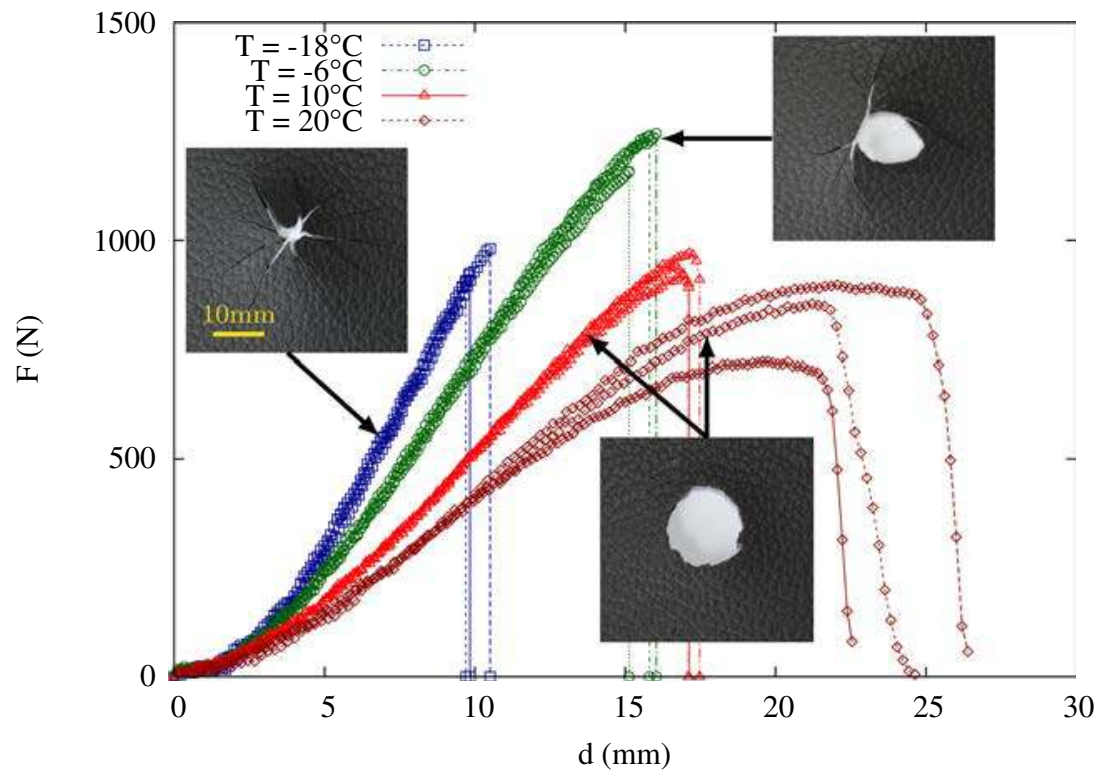

Fig. 4 Load $(F)$ versus deflection $(d)$ curves and fracture surface morphology for unscored thin plate at four selected temperatures: brittle at $-18^{\circ} \mathrm{C}$; mixed at $-6^{\circ} \mathrm{C}$ and ductile at $10^{\circ} \mathrm{C}$ and $20^{\circ} \mathrm{C}$

to lead, without failure, to the final irreversible form of the object. Load versus deflection curves can be considered as the basis of the experimental data. The temperatures and the impact speeds were varied so as to obtain enough data to analyse the deformation and the failure of the thin plates.

For each material and each impact speed condition, around thirty specimens were tested (three samples for each temperature for reproducibility purposes). For the sake of simplicity, only one impact speed $(4.4 \mathrm{~m} / \mathrm{s})$ is shown in the present paper. However, the results obtained were representative of the three other impact speeds. The selected test temperatures were: $\left(-18,-15,-12,-9,-6,-3,0,5,10,15,20^{\circ} \mathrm{C}\right)$. At each test temperature, the test was repeated three times, the experimental data were composed of 33 test results.

\section{Load versus deflection curves}

Figure 4 illustrates the representative shapes of the load versus deflection curves obtained while testing the plate without scoring. For each temperature, three curves were plotted. Typically, the load versus deflection curve was composed of a loading stage (increasing load) followed by a more or less abrupt drop of a load, in a continuous manner. A good reproducibility of the test results can be observed except at $20^{\circ} \mathrm{C}$. The linear part in the loading stage gradually reduced with a decreasing slope (stiffness) when the temperature was increased. In other words, the nonlinear part before the maximum load increased with the temperature. At the same time, the deflection at failure $d_{\mathrm{F}}$ increased whilst the load at failure $F_{\mathrm{F}}$ decreased exhibiting noncontinuous evolution. At $10^{\circ} \mathrm{C}$ a small load softening was observed before the abrupt drop of the load corresponding to the failure of the specimen. At $20^{\circ} \mathrm{C}$ the load drop was gradual i.e. nonvertical.

\section{Fracture surfaces at macroscopic scale}

As recommended by ISO standard [17], the morphologies of the fracture surfaces were systematically observed. All of these fracture surfaces were associated with a type of failure (see arrows in Fig. 4). A star shaped crack was attributed to brittle failure at low temperatures; a circular shape with local irreversible strain (not visible in the figure) was associated with a ductile failure at high temperature and for the transition failure a mixture of both morphologies (star together with circular) was observed.

\section{Through thickness fracture surface}

Attention was paid to the ductile fracture surfaces in Fig. 5. The corresponding picture in Fig. 4, at the macroscopic scale has been reproduced in Fig. 5a. The patterns on the top surface of the skin are clearly visible here. SEM examination of the through thickness surface is shown in Fig. 5b. From the top surface, first a rather flat surface (assumed to be ductile) can be seen followed by a rough surface attributed to the final brittle failure. The appearance of the ductile surface was observed to coincide with that of the load softening mentioned above at $10^{\circ} \mathrm{C}: T_{\mathrm{dth}}$ is likely to be around this temperature for this configuration. Additionally, this view highlighted the presence of significant spherical voids, with an average diameter of about $100 \mu \mathrm{m}$. Figure $5 \mathrm{c}$ shows a closer 

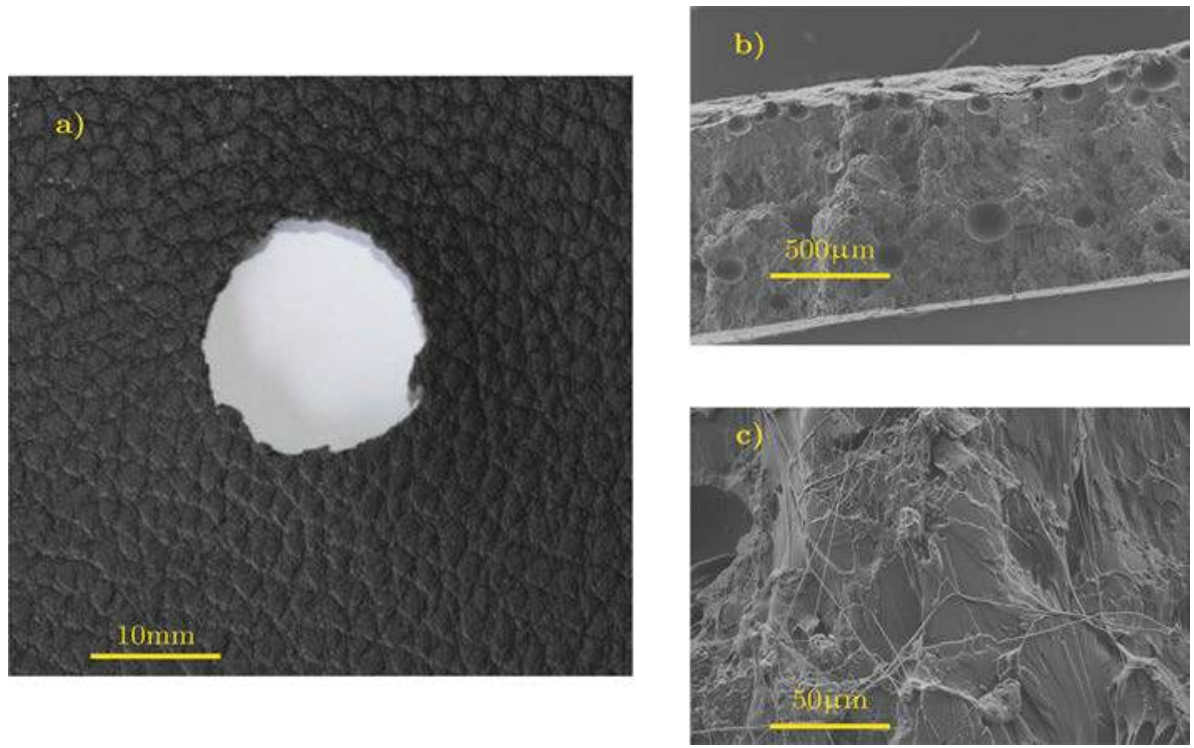

Fig. 5 Fracture surfaces for ductile failure: a top view as in Fig. 4; b through thickness examination; c closer view of the through thickness facture surface showing extended fibrils

view of the ductile surface, where many thin fibrils were seen. They clearly indicates that the material was subjected to large deformation at this location.

\subsubsection{Plates with scoring}

As already mentioned, the PVC skin on the dashboard was scored to enable the airbag deployment along a predefined line within the window. Therefore, impact tests on nonscored samples as discussed in Sect. 3.1.1 were not really appropriate. Additionally, numerous papers about the DBTT determination were based on notched (Charpy or Izod tests) or pre-cracked samples using Fracture Mechanics approaches [19,20,26,27]. Actually, scoring implies, on the one hand a decreasing cross section (remaining ligament); and on the other hand, an increase in the stress triaxiality ratio near the crack tip.

In this section, 24 test results have been analysed, corresponding to 3 tests for each selected test temperature: $\left(-6,-3,0,5,10,15,20,25^{\circ} \mathrm{C}\right)$.

\section{Load versus deflection curves}

The load versus deflection curves for scored samples differed notably from those of unscored samples (Fig. 4). Attention is drawn first to the three tests carried out at $-6^{\circ} \mathrm{C}$ shown in Fig. 6a. A first loading stage was observed up to a load of about $110 \mathrm{~N}$. Then, a first load drop appeared followed by a re-loading stage with apparent oscillations. A second maximum load at $300 \mathrm{~N}$ was reached-except for test\#1 (red square symbols)before a second load drop at a deflection of about $17 \mathrm{~mm}$ for all tests. The slope of the first drop appeared to be same for the three tests. Comments about this sequence of loading will be made in the discussion section. In the following, focus is put on this first loading stage leading to the first drop.

Figure $6 \mathrm{~b}$ displays the typical load versus deflection curves obtained at three characteristic temperatures. It can be seen that all the curves were quasi-linear, with reproducible slopes, whatever the test temperature. Indeed, as mentioned above, at $T=6^{\circ} \mathrm{C}$, the curve is completely linear with a maximum load $F_{\mathrm{F}}$ of $110 \mathrm{~N}$ and a corresponding deflection $d_{\mathrm{F}}$ equal to $2.5 \mathrm{~mm}$. When increasing the test temperature, the load versus deflection curves were still linear with a higher maximum load, together with a greater maximum deflection and a decreasing slope.

It should be noticed that for all tested temperatures (except one test at $-6^{\circ} \mathrm{C}$ as mentioned above), the maximum load reached in the second loading step was the same $(300 \mathrm{~N})$, together with the presence of the oscillations in the load.

Fracture surfaces at the macroscopic scale

The three characteristic aspects of the fracture surfaces are also shown in Fig. $6 \mathrm{~b}$, the scoring being horizontal on the opposite surface (behind the one viewed here). The brittle failure $\left(T=6^{\circ} \mathrm{C}\right)$ exhibited a 

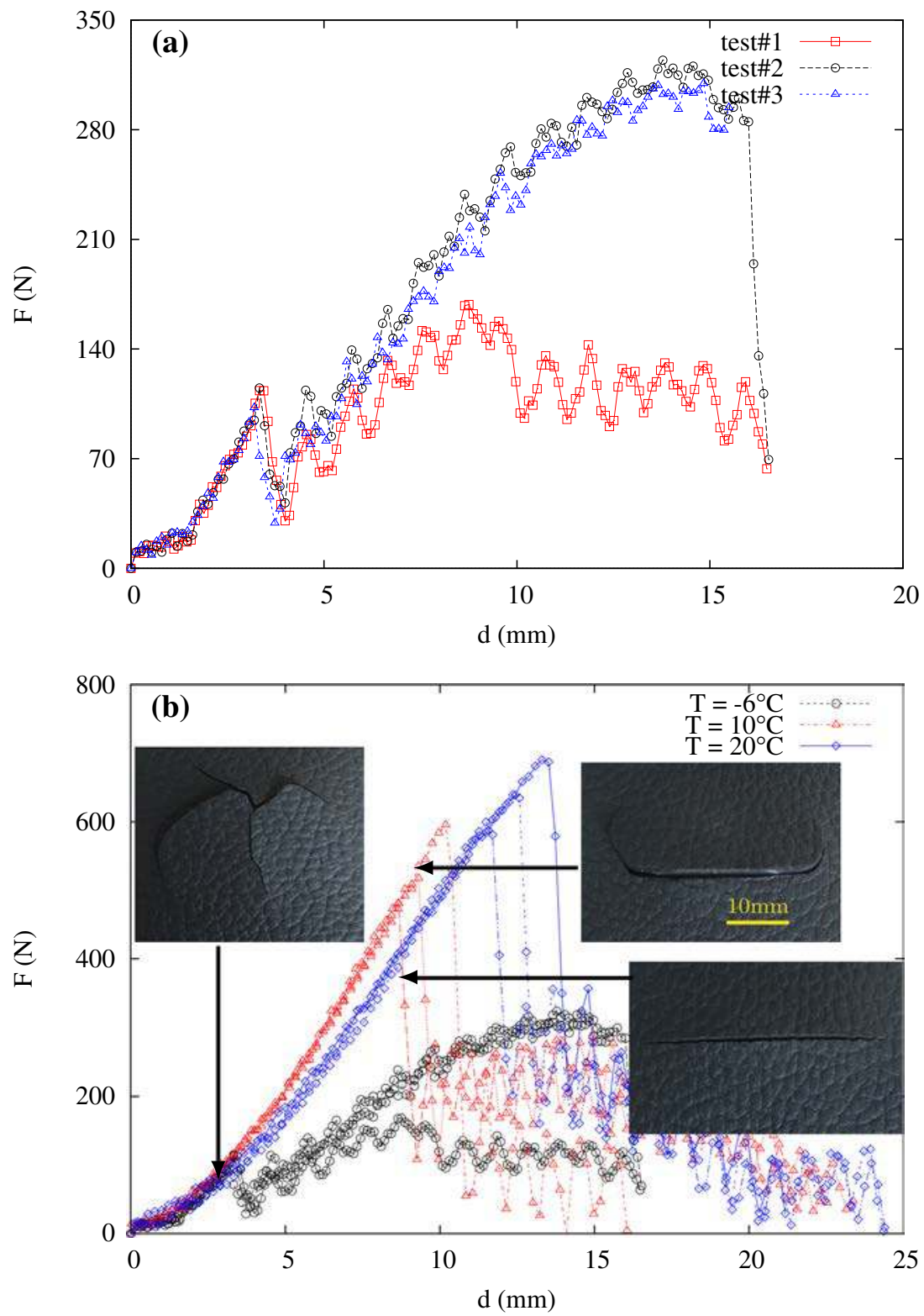

Fig. 6 Load $(F)$ versus deflection $(d)$ curves for scored thin plates: a at $-6{ }^{\circ} \mathrm{C}$; b with fracture surface aspects at three selected temperatures: brittle at $-6^{\circ} \mathrm{C}$; mixed at $10^{\circ} \mathrm{C}$ and ductile at $20^{\circ} \mathrm{C}$

star shaped crack-as on unscored plates-irrespective of the direction of the scoring. The ductile fractured surface corresponding to $20^{\circ} \mathrm{C}$ showed a straight crack consecutive to the through thickness tearing. It can be noticed here that the length of the crack was greater than the diameter of the impactor tip. For the transition regime, like the surface shown for $T=10^{\circ} \mathrm{C}$, bifurcations were highlighted at both ends of the initial straight crack. Initially linear the crack deviated at the end of the process and grew out of the scoring direction.

\section{Through thickness fracture surface}

The same approach as for unscored specimens was used here for ductile failure. In Fig. 7, the through thickness fracture surface clearly showed the initial scoring. Then, the sequence of ductile followed by the brittle surface aspects was identified. 

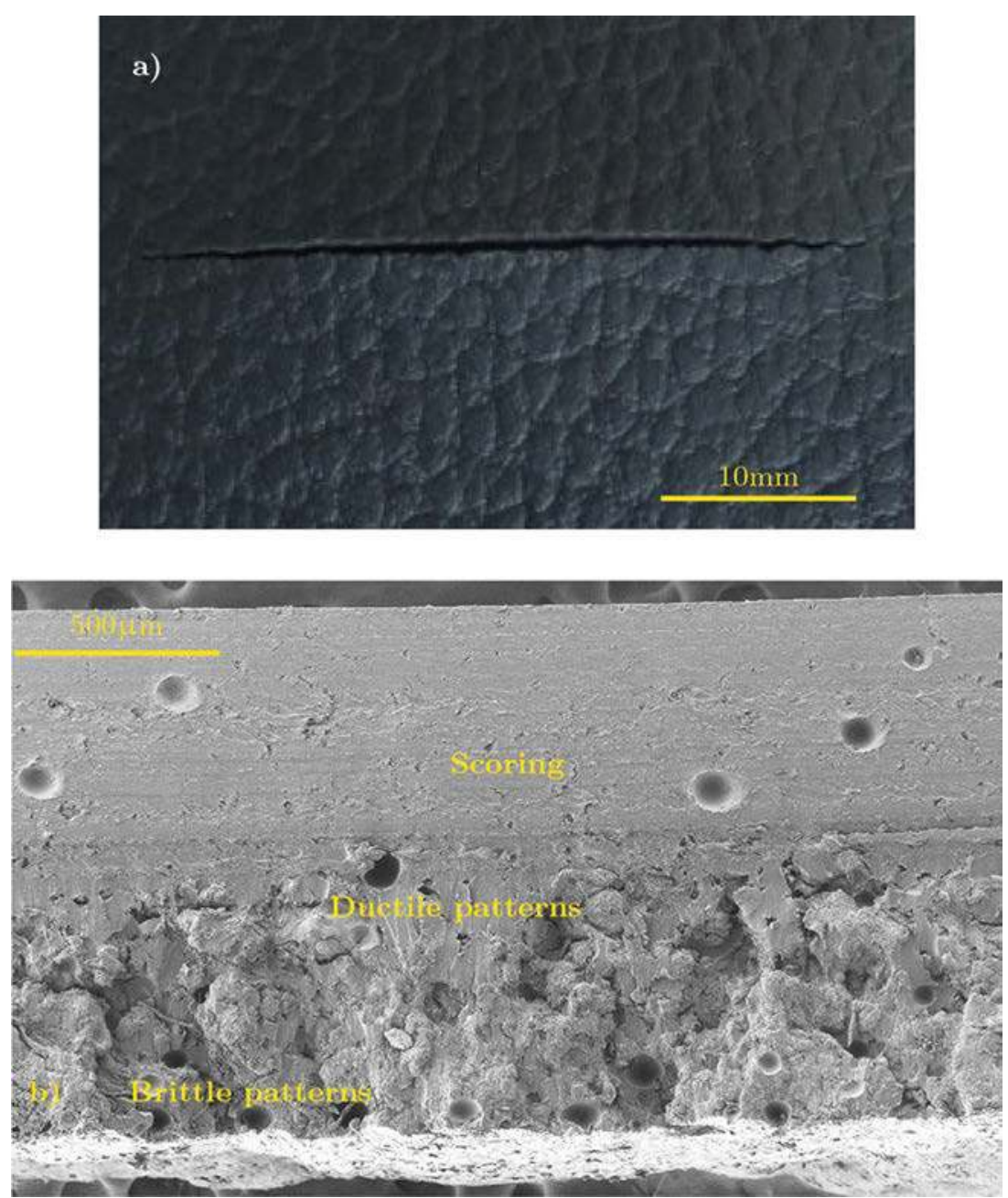

Fig. 7 Fracture surfaces for ductile failure: a top view as in Fig. 6; b through thickness examination

\subsection{Collected mechanical properties}

The trends of three characteristic parameters have been qualitatively discussed in the previous section. The slope of the linear part of the load versus deflection curve consists of the stiffness of the system, representative of the mechanical response. The deflection and the load at break are linked to the failure characteristics. The aim of this section is, on the one hand, a better understanding of the evolution of these parameters as a function of the test temperatures similar to an Eyring representation [28]. On the other hand, this evolution was compared between scored and unscored specimens so as to analyse the effects of the implanted crack like defect.

\subsubsection{Stiffness}

To better estimate the stiffness of the system, the range of loads where the linear part appeared on the load versus deflection curve was first determined. This range was dependent on the test temperature and the nature of the specimen (scored or unscored). $\Delta F / \Delta d$ in $\mathrm{N} / \mathrm{mm}$ was calculated for each of the 57 test results for an impact speed of $4.4 \mathrm{~m} / \mathrm{s}$.

It is to be mentioned that the stiffness of the whole system combined several mechanical parameters such as the Young's modulus and the Poisson ratio of the PVC material, the friction coefficient between the PVC and the metallic impactor, which could change depending on the test temperature: either in nitrogen vapour at low temperatures or in air at high temperatures.

In Fig. 8, it can be observed that increasing the test temperatures resulted in: 


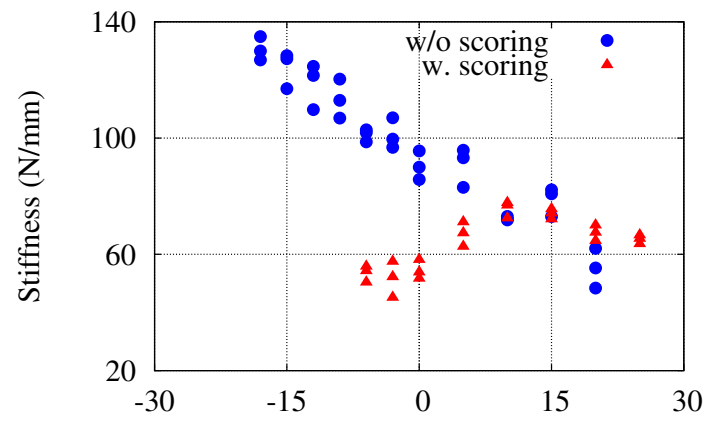

Test temperature $\left({ }^{\circ} \mathrm{C}\right)$

Fig. 8 Comparison of the evolutions of the stiffness for plates with or without scoring

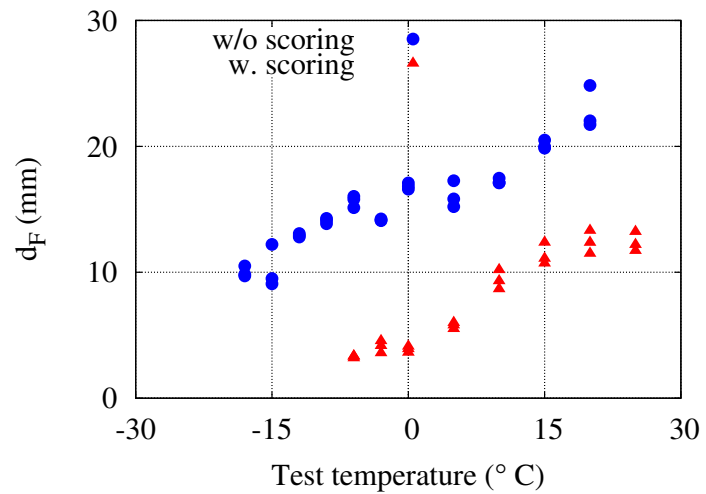

Fig. 9 Comparison of the evolutions of the deflection at failure $\left(d_{\mathrm{F}}\right)$ : a unscored plate; $\mathbf{b}$ scored plate

- a continuous decrease in the stiffness for unscored plates;

- for scored plates, a stabilized value up to $0^{\circ} \mathrm{C}$; and increase up to $10^{\circ} \mathrm{C}$ followed by a decrease.

Results on unscored plates exhibit larger scatter than those of the scored specimens.

\subsubsection{Deflection at failure}

Unscored specimens exhibited larger scatter than the scored ones (Fig. 9) $n$ terms of deflection at break. When the temperature increased, the deflection at break increased. Both curves presented an "S" shaped profile, but the sequences differed between scored and unscored plates. From low to high temperatures, whereas for unscored sample one can distinguish increasing/stable/increasing $d_{\mathrm{F}}$, the scored specimen showed stable/increase/stable profile. The knee points were located at $-6^{\circ} \mathrm{C}$ and $15^{\circ} \mathrm{C}$, respectively, for unscored and scored samples.

\subsubsection{Load at failure}

Again in Fig. 10, the scatter is larger for unscored specimens. Whilst the S-shape curve is clearly visible for scored thin plates, the evolution of $F_{\mathrm{F}}$ is rather complex for unscored specimen. Indeed, the "rainbow shaped" sequence is increasing/stable/decreasing.

\subsection{Fracture energy}

As introduced in Sect. 2.3, the fracture energy $E_{\mathrm{F}}$ combines the three mechanical parameters discussed above. Indeed, it corresponds to the area under the load versus deflection curve up to the load at break. To go further, each test was checked using two criteria based on the trend of the load versus deflection curve (linear or nonlinear) and the shape (star or circular) of the cracks at the macroscopic scale. After the application of these 


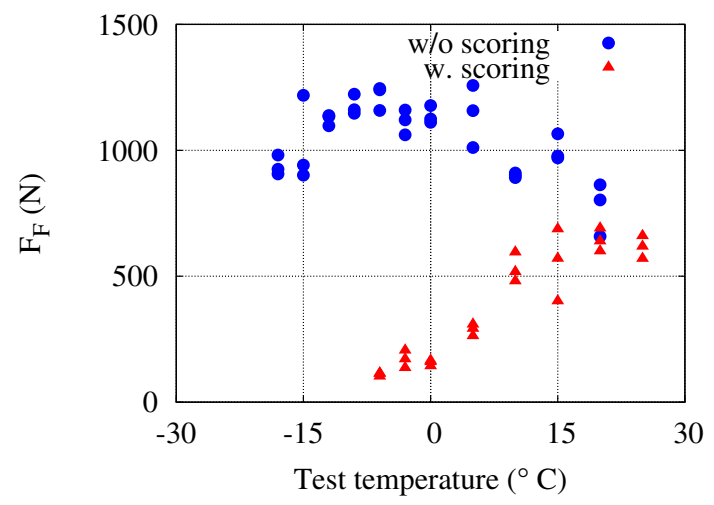

Fig. 10 Comparison of the evolutions of the load at failure $\left(F_{\mathrm{F}}\right)$ : a unscored plate; $\mathbf{b}$ scored plate

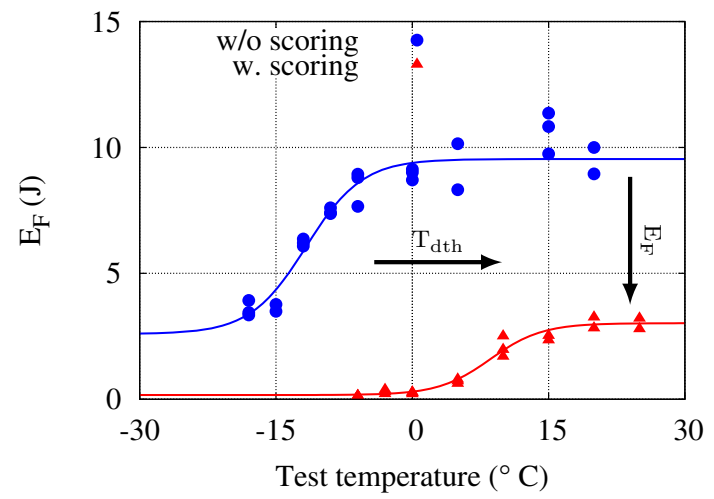

Fig. 11 Evolution of the $E_{\mathrm{F}}$ with respect to the impact speed: effects of the scoring (stress triaxiality)

criteria, 8 and 3 specimens were deleted, respectively, from the unscored and scored thin plates for the impact speed of $4 \mathrm{~m} / \mathrm{s}$. The remaining 46 tests results were used to plot the evolutions of the fracture energy $E_{\mathrm{F}}$ for both samples. It is worth noting that an excellent agreement was found for the values obtained using Eqs. (4) and (5).

Figure 11 illustrates the "S-shaped" of $E_{\mathrm{F}}$ versus the corresponding test temperature $(T)$ at the impact speed of $4.4 \mathrm{~m} / \mathrm{s}$. Similar to what have been reported for many materials including metals [18], the upper shelf named $E_{\mathrm{U}}$ in Eq. 6 can be recognized although exhibiting a large scatter for unscored specimens. From the reduced experimental results, $E_{\mathrm{U}}$ was estimated at approximately $10 \mathrm{~J}$ and $3 \mathrm{~J}$ for unscored and scored samples, respectively. Scoring tends to decrease the ductile fracture energy as indicated by the vertical arrow in Fig. 11. Concerning the lower shelf fracture energy $E_{\mathrm{L}}$, its value decreased from $2.5 \mathrm{~J}$ for unscored samples, down to $0.2 \mathrm{~J}$ for scored specimens.

The same tanh function was used to determine the $T_{\mathrm{dth}}$ for both specimen geometries. It was deduced that $T_{\mathrm{dth}}$ increased from -6 to $14.5^{\circ} \mathrm{C}$ for unscored and scored samples, respectively. The horizontal arrow indicates this shift for the impact speed of $4.4 \mathrm{~mm} / \mathrm{s}$. It should be mentioned here that the thickness of the plate was fixed by the industrial context. Figure 11 seems to indicate that a decrease in the thickness of the specimen (from $1.2 \mathrm{~mm}$ for unscored and $0.6 \mathrm{~mm}$ for scored) induces a shift of the $T_{\mathrm{dth}}$ to the higher temperature, although this effect is mixed with that of the stress triaxiality ratio at the crack tip.

\subsection{Evolution of $T_{\mathrm{dth}}$ with respect to the impact speed}

As mentioned in the introduction, the challenge of this study was to determine the domain of temperature together with the impact speed where the failure of the skin was ductile. The result of the previous Sect. 3.3 at $4.4 \mathrm{~m} / \mathrm{s}$ was extended to the other explored impact speeds: 2, 6 and $10 \mathrm{~m} / \mathrm{s}$. More than 150 supplementary tests were carried out and interpreted so as to reach the above-mentioned objective.

To this end, $T_{\mathrm{dth}}$ values were optimized by using tanh function for other impact speeds. 


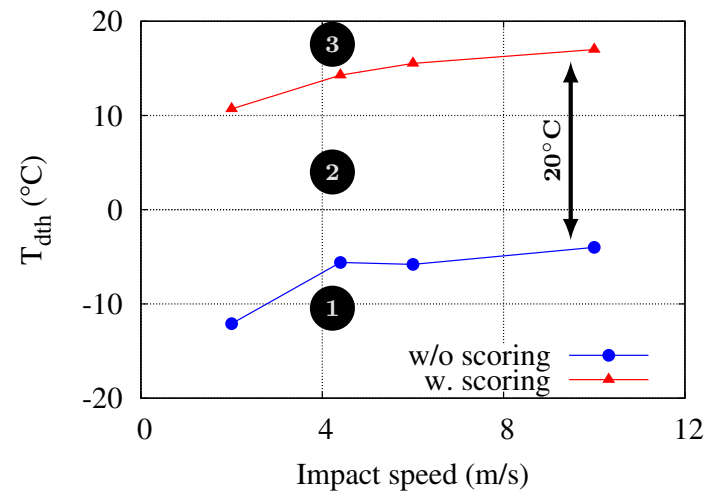

Fig. 12 Effects of the scoring on $T_{\mathrm{dth}}$ as a function of the impact speed

The results for both kinds of specimens are summarized in Fig. 12. For both types of samples, it has been shown that an increase in the impact speed resulted in an increase in $T_{\mathrm{dth}}$. A similar trend was reported in the literature for the DBTT for increasing strain rate. It is to be mentioned that the curves seemed to stabilize beyond $10 \mathrm{~m} / \mathrm{s}$. This could imply that at $25 \mathrm{~m} / \mathrm{s}$ (the impact speed of the airbag deployment) the values at $10 \mathrm{~m} / \mathrm{s}$ could be valid.

Furthermore, the gap of about $20^{\circ} \mathrm{C}$ remained constant whatever the impact speed.

In Fig. 12, the graph has been divided into three domains specified by the numbers inside the black full circles.

- Domain 1: Brittle for both scored ad unscored skins

- Domain 2: Brittle for scored skins-Ductile for unscored skins

- Domain 3: Ductile for both scored and unscored skins

This key diagram can be used to select the geometry of skins related to the temperature and the impact speed so as to obtain net ductile failure.

\section{Discussions}

\subsection{Mechanisms of deformation}

Since the thermostatic chamber where the specimen was located could not be equipped with a video camera, an attempt is made here to propose scenarios linking the fracture surface morphology to the shape of the load-deflection curves.

In the case of a brittle failure a star shaped fracture surface is associated with a linear curve for unscored as well as scored thin skins. The skin failure is assumed to start where the tip of the striker impacts the sample and the cracking propagates in radial paths. The linear profile of the load-deflection curve is related to the bending of the plate. The failure occurs within a stiff plate (generally at low temperature) with small deformation. The crack propagates perpendicularly to the direction of the impact.

For the ductile failure of unscored samples, the starting linear part of the load versus deflection curve still corresponds to the bending of the plate due to the impact. The material being softer, at a critical load, the tip of the impactor crushes the plate provoking the formation of a hemispherical cap, the circular base of which undergoes a shearing at a large strain. During the stretching of this ring, the load stabilizes and even softens. When a critical shear stress/strain is reached, failure within the ring occurs leading to the circular form of the crack. The crack propagates essentially through the thickness in the same direction as the impactor. It is to be noted that in this case the section involved in the fracture process can be approximated by: $\pi \Phi t$ where:

- $\Phi$ is the nominal diameter of the hemispherical striker $(20 \mathrm{~mm})$

$-t$ is the thickness of the plate $(1.2 \mathrm{~mm})$

For scored plates, locally mimicking single edge notch bending (SENB), the impact provokes an opening of the crack with triaxial stresses. The crack propagates only through the remaining ligament until becoming a 


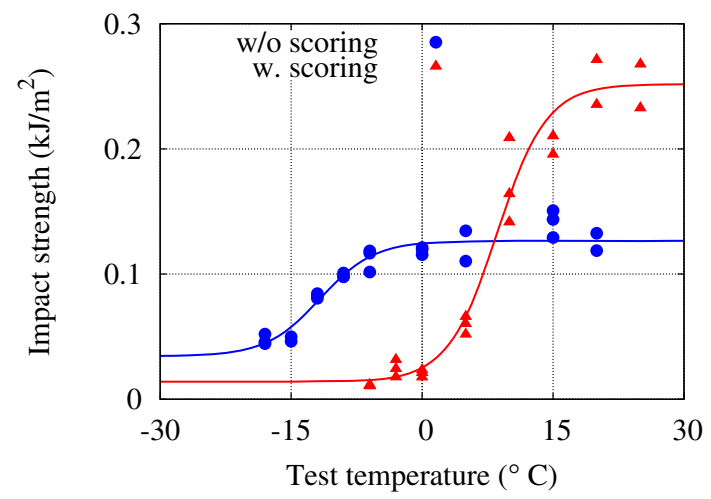

Fig. 13 Evolution of the impact strength with respect to the test temperature

through thickness crack. The last part of the loading consists of a propagating a crack along the direction of the scoring with an inclined crack tip due to the bending. The oscillated reloading viewed in Fig. $6 \mathrm{~b}$ is attributed to this latter stage with the wave propagation due to dynamic effect. In this case, the first drop of the load is related to a net section of about $\Phi(t-a)$; $a$ being the crack depth $(0.6 \mathrm{~mm})$, equal to $t / 2$. Like in fracture mechanics specimens, the (mean stress) hydrostatic pressure is high in comparison with the shear stress for unscored specimens. The effect of the stress triaxiality ratio is known to increase the net stress [29,30].

It can be concluded that the mechanisms of deformation and failure are not the same in the two kinds of specimen. In addition, the volume of material involved in the impact load is greater for the unscored than for scored specimen. Therefore, it was seen that the unscored specimens were more subjected to the effects of:

- the variation of thickness;

- the void (bubble) volume fraction and their clustering

- extrinsic factors such as the temperature heterogeneity or the noncentricity of the impact...

In the authors' opinion these are the reason why the curves of nonscored samples were more scattered.

\subsection{Impact strength}

Figure 11 shows that the plots of the fracture energy for both kinds of specimens where the loaded areas were not the same, as mentioned in the last Sect. 4.1. However, from usual impact tests the impact strength or the impact toughness can be obtained (see for instance [27]). This parameter is the fracture energy per unit fractured surface in $\mathrm{kJ} / \mathrm{m}^{2}$. The knowledge of this parameter is useful for classifying various grades of materials.

The fracture energies determined previously were related to the fractured surfaces $\pi \Phi t$ and $\Phi(t-a)$ for unscored and scored specimens, respectively. In fact, this operation consists of integrating the area under the net stress versus the deflection; the net stress being the load divided by the fractured surface. Figure 13 describes the evolution of the impact strength of the studied plasticized PVC. The upper shelf of the scored specimens was higher than that of the unscored ones. The impact strength is generally measured with notched or pre-cracked specimens. From this last figure, it can be concluded that under these test conditions, the impact strength of the plasticized PVC under study was about $0.25 \mathrm{~kJ} / \mathrm{m}^{2}$.

\section{Concluding remarks}

Tailoring the material and the geometry of the skin of the dashboard around the airbag window is a major concern for the security of passengers by the automotive industry. In the present work a grade of plasticized PVC was tested at various temperatures and impact speeds so as to obtain the domain where a neat ductile tearing of the skin was observed. The temperature for the ductile failure threshold $T_{\mathrm{dth}}$ was introduced instead of using the classical Ductile to Brittle Transition Temperature. About 250 test results consisting of the load versus deflection curves were obtained. The stiffness, the deflection and the load at break were determined for each test condition, after ensuring the reproducibility of the test results. The fracture surface morphologies at 
macroscopic as well as at microscopic scales were systematically analysed. Two criteria based on the shape of the load versus deflection curve and the fracture surface morphologies allowed the selection of the test results giving the ductile failure. For each impact speed, the fracture energy plotted with respect to the test temperatures showed a tanh function profile. Therefore, the value of $T_{\mathrm{dth}}$ was optimized by fitting the $\tanh$ function parameters with the experimental data for scored and unscored thin plates. It was shown that:

- for both geometries, $T_{\mathrm{dth}}$ increased with the explored impact speeds: $2 \mathrm{~m} / \mathrm{s}$ to $10 \mathrm{~m} / \mathrm{s}$;

- a gap of $20^{\circ} \mathrm{C}$ on $T_{\mathrm{dth}}$ was highlighted between scored and unscored specimens whatever the impact speed;

- $T_{\mathrm{dth}}$ plots seemed to exhibit saturation at high impact speed.

With this comprehensive experimental data, the impact strength of the plasticized PVC under study was estimated to be around $0.25 \mathrm{~kJ} / \mathrm{m}^{2}$.

Acknowledgements The authors would like to acknowledge Gabriel Dalloux and Grégory Martin (Nakan Company) for their fruitful discussions. Amandine Saintot (Catalyse Company) is acknowledged for technical assistance.

\section{References}

1. Cox, K.R., Robertson, R.E.: Controlling Failure of Polymer Skin/Foam Bilaminate Sheets, SAE Technical Paper 2007-011216. SAE International, Warrendale (2007)

2. Brown, N., Ward, I.M.: The influence of morphology and molecular weight on ductile-brittle transitions in linear polyethylene. J. Mater. Sci. 18, 1405-1420 (1983)

3. Corté, L.: Renforcement des polymères semi-cristallins, PhD thesis, ESPCI ParisTech (in French) (2006)

4. Jang, B.Z., Uhlmann, D.R., Sande, J.B.V.: Ductile-brittle transition in polymers. J. Appl. Polym. Sci. 11, 3409-3420 (1984)

5. Kambour, R.P., Bernier, G.A.: Craze formation yield stress and the so-called Ductile-Brittle transition in glassy polymers. Macromolecules 1(2), 190-191 (1968)

6. Serenko, O.A., Goncharuk, G.P., Obolonkova, E.S., Bazhenov, S.L.: The brittle-ductile transition in rubber-filled polymers. Polym. Sci. Ser. A 48(3), 302-313 (2006)

7. van Melick, H.G.H., Govaert, L.E., Meijer, H.E.H.: Prediction of brittle-to-ductile transitions in polystyrene. Polymer 44(2), 457-465 (2003)

8. Collyer, A.A.: Rubber Toughened Engineering Plastics. Springer, Berlin (2012)

9. Laiarinandrasana, L., Nziakou, Y., Halary, J.L.: Fracture behavior of amorphous and semicrystalline blends of poly(vinylidene fluoride) and poly(methyl methacrylate). J. Polym. Sci. Part B: Polym. Phys. 50(24), 1740-1747 (2012)

10. Challier, M., Besson, J., Laiarinandrasana, L., Piques, R.: Damage and fracture of polyvinylidene fluoride (PVDF) at $20^{\circ} \mathrm{C}$ : experiments and modelling. Eng. Fract. Mech. 73, 79-90 (2006)

11. Schiller, M., Additives, P.V.C.: Performance, Chemistry, Developments and Sustainability. Carl Hanser Verlag GmbH \& Co. KG, München (2015)

12. Wilkes, C.E., Summers, J.W., Daniels, C.A., Berard, M.T.: PVC Handbook. Hanser, Munich, Cincinnati (2005)

13. Ebewele, R.O.: Polymer Science and Technology. CRC Press, London (2000)

14. Wypych, G.: PVC Degradation and Stabilization. Elsevier, New York (2020)

15. Tcharkhtchi, A.: Rotomoulage de pièces en matière thermoplastique. Techniques de l'ingénieur Plasturgie : fabrications de corps creux, de films et de fils, TIB149DUO. am3706 (2004). https://www.techniques-ingenieur.fr/base-documentaire/ materiaux-th11/plasturgie-fabrications-de-corps-creux-de-films-et-de-fils-42149210/rotomoulage-de-pieces-en-matierethermoplastique-am3706/

16. Crawford, R.J., Throne, J.L.: 2-Rotational Molding Polymers. In: Crawford, R.J., Throne, J.L. (eds.) Rotational Molding Technology, pp. 19-68. William Andrew Publishing, Norwich (2002)

17. ISO 6603-2:2000, Plastics—Determination of puncture impact behaviour of rigid plastics—Part 2: Instrumented impact testing. https://www.iso.org/fr/standard/25172.html

18. Bruchhausen, M., Holmstrom, S., Lapetite, J.-M., Ripplinger, S.: On the determination of the ductile to brittle transition temperature from small punch tests on Grade 91 ferritic-martensitic steel. Int. J. Press. Vessels Pip. 155, 27-34 (2017)

19. Lei, W.S., Yan, X.Q., Yao, M.: Determination of characteristic transition temperature of low-temperature brittleness in mild steel. Eng. Fract. Mech. 46, 571-581 (1993)

20. Bohme, W., MacGillivray, H.J.: Experience with instrumented Charpy tests obtained by a DVM round-robin and further development. In: van Walle, E. (ed.) Evaluating Material Properties by Dynamic Testing ESIS 20, pp. 1-23. Mechanical Engineering Publications, London (1996)

21. Hale, G., Ramsteiner, F.: J-fracture toughness of polymers at slow speed. In: Moore, D.R., Pavan, A., Williams, J.G. (eds.) Mechanics testing methods for polymers, adhesives and composites, vol. 28, pp. 123-157. ESIS Publication, London (2001)

22. Bulloch, J.H.: A study concerning material fracture toughness and some small punch test data for low alloy steels. Eng. Fail. Anal. 11(4), 635-653 (2004)

23. Williams, J.G.: $K_{C}$ and $G_{C}$ at low speed for polymers. In: Moore, D.R., Pavan, A., Williams, J.G. (eds.) Fracture Mechanics Testing Methods for Polymers, Adhesives and Composites, vol. 28, pp. 159-175. ESIS Publication, London (2001)

24. MacGillivray, H.J.: Fracture toughness of polymers at impact speed. In: Moore, D.R., Pavan, A., Williams, J.G. (eds.) Fracture Mechanics Testing Methods for Polymers, Adhesives and Composites, vol. 28, pp. 159-175. ESIS Publication, London (2001)

25. Bernard, C.A., Correia, J.P.M., Bahlouli, N., Ahzi, S.: Numerical simulation of plug-assisted thermoforming: application to polystyrene. Key Eng. Mater. 554-557, 1602-1610 (2013) 
26. Martin, P.J., Duncan, P.: The role of plug design in determining wall thickness distribution in thermoforming. Polym. Eng. Sci. 47, 804-813 (2007)

27. Tanguy, B., Bouchet, C., Bugat, S., Besson, J.: Local approach to fracture based prediction of the $\Delta T 56 \mathrm{~J}$ and $\Delta T K_{I c} 100$ shifts due to irradiation for an A508 pressure vessel steel. Eng. Fract. Mech. 73, 191-206 (2006)

28. Eyring, H.: Viscosity, plasticity and diffusion as examples of absolute reaction rates. J. Chem. Phys. 4, $283-291$ (1936)

29. Laiarinandrasana, L., Besson, J., Lafarge, M., Hochstetter, G.: Temperature dependent mechanical behaviour of PVDF: experiments and numerical modelling. Int. J. Plast. 25, 130-1324 (2009)

30. Boisot, G., Laiarinandrasana, L., Besson, J., Fond, C., Hochstetter, G.: Int. J. Solids Struct. 48, 264-2654 (2011) 